\section{THE CHESTNUT TREE OF MOUNT ETNA}

$T$ HE traveller in Sicily will recollect the little village of Giarre, about half way between Messina and Catania; and since the opening of the railway between these cities, with a station at no great distance from its principal street. On the sea-side below the town is the shipping port of Riposto, and between Riposto and Giarre lies a fertile plain, rich in olive and vine-yards. Giarre itself has not much to boast of, except perhaps it might do so of the glorious views to be seen from the slight elevation on which it stands. One long principal street, a large plain chapel, a very second-rate inn, and then there is nothing more to be said of the village. It is, however, the nearest town with an inn to the famous giant chesinut tree of Mount Etna, and as such is visited by tourists. This fine old tree grows in the Bosco or woody region close above the town and on the slope of Mount Etna. A narrow, steep road, gradually ascending, leads from Giarre to La Macchia, the broad bed of a river now (in the end of May) rolling down nought but clouds of dust, is passed, and the lava beds formed by the eruptions of $I 689$ and $I 735$ are traversed, and at last $\mathrm{S}$. Alfio is reached. This village is about four and a half miles from Giarre, and from it a very fine view of Etna is obtained. The moun. tain, however, from this side look low and by no means as imposing as when seen from the sea. A little beyond S. Alfio the road turns to the left still leading upwards; until all of a sudden the giant tree breaks upon the view, the road itself running through its very midst. It stands about 4,000 feet above the sea level, and it requires a good three and a half hours to walk to it from Giarre.

It has been calculated that this tree is about $r, \infty 00$ years of age. It is a tree, therefore, old enough to have its early history lost in myth; but still it has its story; and this story tells us that long ago a certain Queen of Aragon was passing by this way, when, from the effects of the weather, she and her suite, which consisted of one hundred mounted persons, took shelter under the shadow of its trunk and boughs, and so to this day and from this fact it is known as the Castagno di Cento Cavalli. This story is said to be generally believed, and, at any rate, does not appear to have been much discussed. Not so the tree; and very many opinions may be quoted all more less differing as to its age and size. Some believe, or have believed, that the tree was as large as the story tells us it was, that the interior of the vast trunk has since then decayed away; leaving a number of separate pieces, each large enough to

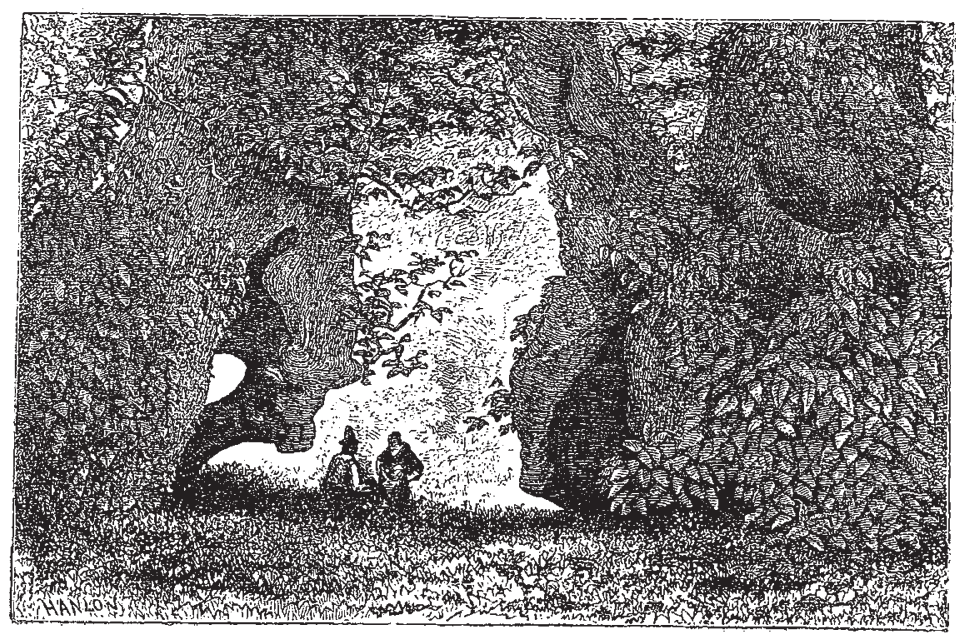

THE CHESTNUT TREE OF MOUNT ETNA

form a big tree, which pieces are covered with bark only on their outer surface. Others assert that there were here several large trees, more or less joined together, and demonstrate on the pieces of these trees still standing the barky layers surrounding the whole of their stems.

Not very long ago there were still four pieces standing, each of them of the dimensions of a very large tree. In the space surrounded by these pieces stood a hut, in which the annual crop of chestnut fruit was stored. One of these trees, or portions of the tree, has since disappeared. The hut has now been removed, and the road, sufficiently wide to allow of a carriage, runs between the remaining pieces and over the ground on which the hut was built. As you approach, one large piece of the tree is to the left-hand side of the road, and two larger pieces are to the right. It is very probable that many of the pieces believed to have belonged to the one original vast stem, were really stems themselves of independent trees, and such would appear to be the case with the large trunk to the left of the present roadway. But there is a strong probability that the two immense pieces to the right of the road were at one time united, and that they form part of the original tree. The annexed woodcut is from a photograph of these pieces. Both of them are deeply hollowed out. The base of the trunk to the right of the woodcut is very much decayed away, and several men could shelter in it ; and the portions of the stems seen on looking at the picture are devoid of true bark. If these two portions once formed a single stem, then, indeed, though it might not have thrown a shadow sufficiently large to shade a hundred horsemen, yet it must have been a very giant among all the forest trees. Even now, in its decadence, the three stems are objects of sufficient interest to lead us to ask for them the reader's attention. E. P. W.

\section{SCIENCE IN PLAIN ENGLISH}

II.

I $\mathrm{N}$ considering the importance of Technical Education with reference to the practical arts, and the claims of Science as an element of culture, we are led to study the methods of teaching.

It has been the custom in English to borrow the technical terms of Science from the so-called "learned languages," particularly Latin and Greek. To such an extent has this been carried that unless a term bears the marks of such a derivation it is hardly recognised by the public as a technical term. 